\title{
The grammar of causatives and the conceptual structure of events*
}

SUZANNE KEMMER and ARIE VERHAGEN

\section{Abstract}

Analytic causative constructions can best be described as extensions of simpler kinds of expressions, rather than as reductions from more complex underlying structures. In particular, causatives of intransitive predicates (e.g. I made Mary cry) are viewed as modelled on simple two-participant clauses (like I ate the cake), and causatives of transitive predicates (e.g. He had the servant taste the food) are seen as modelled on simple threeparticipant clauses (like I gave Mary a flower, or She broke it with a hammer-i.e. mainly ditransitive and instrumental clause types).

One especially important advantage of this approach is that it offers an explanatory semantic account of the variation of case markings found in causative constructions (such as the rather general alternation of dative, or other non-oblique, with instrumental), it predicts that such variation is related systematically to the semantics of case markings in simple clauses, which is in fact the case. It is argued that accounts of case marking of causees formulated strictly in terms of a formal hierarchy of cases cannot be adequate, given the semantic factors affecting the choice of case. The marking of the causee is a consequence of conceived differences in its role in the causal event, which relate to such aspects of event structure as (in)directness of causation and (relatedly) degree of agency and affectedness of participants. Such factors are elements of certain general conceptual models of causation.

This approach not only has wider empirical coverage than syntactic, hierarchy-based accounts, but is simple, unified, has greater explanatory power both for cross-linguistic variation and for intricate intralinguistic distributional facts; finally, it accords with a cognitively-based view of language, in which the knowledge underlying grammar is not qualitatively different from other aspects of human understanding and reasoning.

\section{Introduction}

The grammar of causative constructions has inspired what is probably one of the most extensive literatures in modern Linguistics. Such intensive 
scrutiny has no doubt been motivated in part by the fascinating complexities of causatives both within particular languages and cross-linguistically; but, in addition, there seems to have been a tacit recognition by many linguists that an understanding of causatives is fundamental to an understanding of clause structure as a whole.

A common approach to causatives is to consider them to be derived by reduction, either of clauses or predicates. Comrie (1976: 303), for example, states that causative constructions result from "the compression of an underlying complex structure with embedding into a derived structure simplex sentence".

The basic idea in this approach is to posit an underlying biclausal structure and use some syntactic manipulations to arrive at a single clause (e.g. raising rules, clause union, etc.). This type of account is found in a number of derivational syntactic theories of the last twenty years. In certain more recent lexical approaches, the idea is to start out with two (semantic) predicates and then use some mechanism involving merger of the arguments to create a single predicate-argument structure. ${ }^{1}$ Despite the differences in mechanics, such analyses share the basic idea of reduction of a larger or more complex linguistic structure to a smaller or simpler one.

Our view of causatives is in some ways the opposite: causative structures are seen, instead, as built up from simpler structural/conceptual units, in the sense that they relate (non-derivationally) to more basic clause types. The primary intent of this paper is to lay out a way of understanding some widespread causative patterns in a manner consistent with basic assumptions and findings in the field of Cognitive Linguistics. The analysis is by no means intended to be exhaustive; but we do claim that it has several advantages as a framework for further cross-linguistic investigation and for investigation into the details of particular causative structures in individual languages.

We will begin with some basic concepts and terminology, and then in section 3 present some well-known typological generalizations regarding causative structures. In sections 4.1 and 4.2 we offer an account of these generalizations along the lines intimated above. In further support of our analysis, we present some additional cross-linguistic considerations in section 4.3, and in section 4.4 some results of a corpus-based case study of causatives in Dutch. This case study shows how our analysis can be applied insightfully to detailed data from a single language. Thus, the analysis as a whole is empirically valid for the basic patterns discussed, both at the cross-linguistic level and at the level of an individual language. In the final section of the paper, we will sketch some of the advantages 
of this type of approach which distinguish it from the "reduction" approaches, and some of its implications for grammatical theory.

\section{Basic notions}

To illustrate our notion of "causative construction" it is useful to begin with analytic causatives. An analytic causative is a two-verb structure that expresses a predicate of causation and a predicate of effect. ${ }^{2}$ Thus, English expressions like I made him leave, Seeing him again caused her to lose her composure, and We let her come along are analytic causative constructions. To use such a structure, a speaker must view one predicate, which we will call the effected predicate, as causally dependent on some action of the subject of the sentence. ${ }^{3}$

The reference above to the speaker's "view" is important; we must emphasize that in talking about causation we are not referring to some notion of causation in the physical world, but rather to the human conceptualization of causation, which must be based in some fundamental mode or modes of chunking and organizing perceived reality that allows humans to interact successfully with their physical and social environment. We assume that language is a good source of evidence for discovering at least some of the conceptual structures associated with causation. We will not attempt here to justify the structures we posit with evidence from non-linguistic domains, although we recognize that such additional justification is highly desirable. In the course of this paper, we suggest that causative structures relate to specific "cognitive models" (Lakoff 1987 and elsewhere), which represent integrated conceptual structures with specifiable properties.

Returning now to the linguistic expression of causation, we wish to further delimit the range of structures we are interested in. It is not the case that all constructions expressing two events viewed as causally related fall under our definition of causative constructions. ("Event" here includes action, process and state predicates.) Expressions such as They insulted me, so I left are excluded, even though they contain two predicates with a causal relation between them. The hallmark of the causative construction, which sets it apart from the latter kind of expression, is that in the causative construction the actual causing event is not overtly specified by one of the predicates. All that is expressed by the predicate representing the causing event, which we will call the "causal predicate", is the pure notion of cause (or the closely related one of enablement; cf. below), without more specific lexical content. (Contrast INSULT in the above example, which describes what type of event caused the leaving.) This necessarily means that the causal predicate is conceptually dependent 
on the effected predicate; in other words, causal predicates necessarily evoke the idea of another action or state.

Languages tend to have a construction specifically designed to express causative relationships in which the causing event is not elaborated beyond the notion of cause (although often certain schematic force dynamic relations are expressed, like permission, directness of effect, etc.; cf. below). Such constructions show formal differences from two-clause structures in languages that overtly distinguish monoclausal and biclausal structures. Most typically, the causative constructions show affinities to one-clause structures.

Considering morphological features, for example, analytic causative constructions often consist of two verbs, only one of which has all the formal trappings of a normal verbal element. Thus in English and many other European languages, only one of the two verbs involved in the structure occurs with tense/aspect marking; the other verb is an infinitive. Considering syntax, it has been amply documented in the generative literature on analytic causative constructions that they tend to display behavior associated with single-clause structures when found in conjunction with certain syntactic rules such as clitic placement, passive, and "object-raising" constructions (see, for example, Aissen and Perlmutter 1983 and Gibson and Raposo 1986). ${ }^{4}$

In our view, the widespread morphological and syntactic indications of monoclausality tell us something, namely that these two predicates are conceptually close, closer than the predicates in structures in which both the predicate indicating cause and that indicating result are equally specific and conceptually independent.

The above characterization of causative constructions easily extends to morphological causatives: in that case, the causal and effected predicate happen to be expressed in one word composed of two morphemes, one indicating the causal predicate and the other the effected predicate (e.g. Songhai $n g a-n d i$ [eat-CAUS] 'make eat'). Again, the causal predicate is non-specific as to the causing action designated. In languages with morphological causatives, the causal predicate is not only semantically but morphologically dependent on the effected predicate; and the causative structure is more obviously monoclausal (although see Kuroda 1992 for evidence of some "biclausal" behavior with the Japanese productive causative $-(s)$ ase $)$.

It is also possible to consider as causative constructions what are often referred to as lexical causatives, i.e. verbs that are discernibly semantically causative, but are not formally analyzable into two morphemes (e.g. English break, open, Japanese koros 'kill', age 'raise', etc.). Such verbs might be said to involve maximal conceptual closeness of the causal and 
effected predicate (cf. Haiman 1983; Lakoff 1987). We will not be directly concerned with lexical causatives in this paper, although we will make passing reference to them at various points.

The causative constructions of concern here can be defined as analyzable structures with a conceptually dependent causal predicate. Going along with its conceptually dependent status, the causal predicate is conceptually "bare bones": it does not introduce the kinds of specific semantic roles evoked by a fully elaborated predicate expressing a cause. In They made me leave, MAKE does not have any highly specific semantic content that could determine semantic roles (of the type agent, patient, etc.) in relation to itself. In contrast, in the causing event in two-clause structures like They insulted me, so I left, the verb has its usual constellation of specific roles (in this case, two roles, agent and experiencer/ patient), which occur independently of its use in an expression of cause and effect.

Despite the lack of specific semantic roles associated with the causal predicate, we claim that there are, in fact, semantic roles involved in a causative event. These roles are instantiated by what we will refer to as the core participants in causative events: the causer, the causee, and (in certain causative events) the affectee. The following sentences will serve to illustrate these notions:
a. She made it fall over
i. by pushing on it.
ii. by rolling the ball into it.
b. She made him cough.
c. She made him type the letter.
d. She had him type the letter.
e. She let the water run out of the bathtub.
f. She let him eat some of the brownies.

The causer in each of these sentences is the entity viewed as causing the entire event, i.e. the subject of the sentence, she. ${ }^{5}$ The causee is the entity carrying out the activity designated by the effected predicate, viz. it, him, the water, which are the participants that respectively fall over, cough / type the letter / eat some of the brownies, and run out of the bathtub. (Some languages allow the causee to remain implicit.) The affectee, where present, is the entity that is the endpoint of the energy (literal or metaphorical) expended in the entire causative event, here expressed by the noun phrases the letter and some of the brownies in (1d) and (1f) ${ }^{6}$ We take these roles as theoretically significant, rather than as convenient labels, and will claim below that they are more crucial than any roles selected by individual predicates in the causative construction. 
It might be noticed from the examples in (1) that different "force dynamic" configurations (in the sense of Talmy 1988) are possible with causative constructions. Relations of cause and effect expressed in language fall into certain specific semantic types. Here, we mention the types that cross-linguistic evidence indicates to be highly relevant to analytic and morphological causative constructions. ${ }^{7}$ These types, it must be emphasized, involve highly schematic semantic parameters. Causal predicates do not appear to be any more fleshed out in their lexical semantics than in terms of the types of force-dynamic properties sketched below.

Three parameters recur in connection with distinctions between causative structures in a given language: physical vs. non-physical causation (where physical causation correlates with a low degree of autonomy or control on the part of the causee); direct vs. mediated causation, where the latter involves some conceived intermediary entity or force; and cause per se vs. enablement and permission. These parameters interact, producing the following main types:

Direct physical causation, in which the causer acts on the causee without any intervening entity, e.g. the situation described in (1ai); indirect physical causation, in which the causer brings about the effected event through some intermediary physical process (1aii); and inducive causation, in which the causee is an agentive entity who is caused to act by some nonphysical means, typically by some verbal stimulus produced by the causer (1c, 1d). According to Talmy's force dynamic analysis (Talmy 1988), all of these types involve exertion of (concrete or abstract) force on the part of the causee; the successful accomplishment of the effected event involves overcoming a conceived resistance on the part of the causee. A fourth type, enablement/permission, involves not the exertion of force on an entity to bring about an event that otherwise would not have happened, but the removal by the causer of a conceived barrier that was preventing the causee from carrying out or undergoing the effected event. Enablement refers to the case where the barrier is physical (1e) and permission to the case where the barrier is social or sociophysical in nature (1f); we can thus consider enablement and permission as subvarieties of one type.

In any given language, of course, a causative structure might cover more than one type; for example Dutch laten expresses inducive causation as well as enablement/permission, and English make can be used in the expression of situations of direct physical, indirect physical, or inducive causation (1ai, 1aii, and 1c, respectively; and $1 \mathrm{~b}$ ambiguously for all three, given the right contexts). It is also often the case that different causative structures in a language exist, and where this occurs, the structures are most typically associated with one or another type of causation. Differences in structure can be exploited, in most or perhaps all languages, 
to express differences along the above-named parameters. Note for example the difference between English I moved the chair and I made the chair move; the first is most appropriate for situations of direct physical causation, while the second is most appropriate for causation involving some perceived mediacy, e.g. by pressing the button; by pulling on the rope, by catching it with my foot, etc.

In addition, there are a number of phenomena observed which place limits on the direct contrasts available with the causative structures in a given language. For example, it is often the case that where different causative structures exist in a given language, not every effected predicate can occur in every such structure. Some structures are quite limited in the predicates they occur with, while others are freer. ${ }^{8}$ Other alternations, such as case choice, may be likewise restricted to a subset of predicates (as will be seen in section 4.2). And lastly, particular structures might be restricted to specific types of causers and causees (e.g. the English have causative, which is restricted to human causees).

Such restrictions are simply the limiting case of the general situation found with causative constructions, namely that each such structure is associated with a particular semantic configuration of participant types and force-dynamic relations that it most typically expresses. Causative constructions range from very restricted, correlating with a high degree of semantic specificity, to very general, correlating with highly schematic semantics. Intermediate cases include constructions that are associated with a relatively specific prototypical semantic configuration but which can be pressed into service to cover situations ranging over various causative types.

Thus, despite potential ambiguity for some structures, and the lack of a full set of contrasts for others, causative constructions have their own characteristic semantics. Careful attention to pairwise contrasts and the most natural readings or contexts associated with each construction is a strong source of evidence for such semantic properties (cf. Shibatani 1976). Observations of this type will be used to support our analyses throughout this paper. We furthermore hypothesize that semantic differences between alternative constructions, where such alternatives exist, will emerge when they are observed in context in large numbers of actual usage events; support for this is found in our study of a Dutch text corpus in section 4.4.

The semantic causative types distinguished above represent a more elaborated set of contrasts than many or most languages have distinct structures to express. Many languages make a systematic two-way contrast between analyzable causative constructions signifying more direct vs. more mediated causation (often referred to as a contrast between 
"direct" and "indirect" causation). What types of situations languages choose to treat as direct and which as mediated varies, although there is a general correlation between physical manipulation or control of the causee and direct causation marking, on the one hand, and inducive or permission/enabling causation and indirect causation marking, on the other. However, the English examples in (1) show that the properties outlined above interact in a more complex way than this general correlation suggests. For example, a decrease in (the speaker's conception of) the autonomy of the causee in a situation of inducive causation facilitates the use of a causative structure associated in English with relatively more direct causation, as in (1c), rather than the structure most typically associated with inducive causation, viz. the have causative illustrated in (1d). (Make therefore expresses a degree of directness of causation that is intermediate between that of lexical causatives, where they exist for a given predicate, and the have causative.)

The reason that analysts have had difficulty explicating the notion of "direct" vs. "indirect" causation is that the contrast is partially independent of the perceptual factors involved in the described situation: it is a conceptual, not a perceptual contrast. Speakers' construal of a given situation in terms of these semantic properties and, more generally, the three parameters discussed above, plays an obvious role in the coding of contrasts where choice is available (cf. Langacker 1987, 1991).

Our approach provides a fruitful framework for the analysis of semantic differences between causative structures, in particular the distinction between more direct and less direct causation associated with analyzable causative constructions. In section 4.2 , we show how the case markers associated with such causative structures can be used to signal differences of this type. In section 4.4 we show how similar differences are associated with different causative verbs in Dutch. In our view, such differences derive from the cognitive models associated with causative constructions and/or their associated structural elements (e.g. case markers).

\section{A cross-linguistic look at causative constructions}

The first observation that can be made on examining causative constructions cross-linguistically is that there is a widespread tendency towards formal differentiation of two kinds of causative constructions: causatives of one-participant events and causatives of two-participant events. In other words, sentences of the type I made Mary cry and I made her eat some cake show up as formally different in particular ways, depending on the language. We will term causative constructions in which the effected predicate is a one-participant event "intransitive causative con- 
structions" or ICs, while causative constructions in which the effected predicate is a two-participant event are called "transitive causative constructions" or TCs. ${ }^{9}$

Although there are a number of ways in which a language can differentiate between these two causative types, by far the greatest amount of attention in the literature (both generative and broad-based typological) has been devoted to the case marking of the causee. ${ }^{10} \mathrm{~A}$ very widespread pattern found is the following: The case marking on the causee is different, depending on whether it is in an IC or a TC. The following examples from Basque illustrate this situation. ${ }^{11}$
a. Hark
Patxeko
sar erazi $d u$.
3.SG.ERG Pacheko.ABS enter make AUX
'S/he has made Pacheco enter.'

\section{b. Haiek Letona-ri liburu-a galdu erazi zioten. they-ERG Letona-DAT book-ABS lose make AUX 'They made Letona lose the book.'}

Here the causee appears in absolutive case, the case marking associated in Basque with direct objects, in the IC in (2a), while the causee in (2b) is in the dative, the case used for indirect objects.

This pattern was incorporated in Comrie's well-known account of case marking in causative constructions (Comrie 1976, 1981). His account, like many of those proposed in the literature, did not focus directly on the differences between ICs and TCs but on attempting to predict which clausal participant will get assigned which case.

Comrie's account invokes the case hierarchy, Subject $>$ Direct Object $>$ Indirect Object $>$ Other Oblique to account for the cases that occur on causees cross-linguistically. He noted that it is the causee, and not any of the other participants, whose case marking seems to change depending on what other participants there are in the clause. The principle he elucidated is the following: the causee receives the next case further down on the hierarchy after all the other participants have been assigned cases from the beginning of the hierarchy. In ICs, for example, the causer gets the subject case (however that is realized language-specifically); the causee, the only other participant, receives the next case on the hierarchy, which is direct object case (e.g. accusative or other exponent of direct object). In TCs, the direct object case is taken by the affectee, leaving the causee to be assigned the next one down (indirect object, usually dative case). In causatives of ditransitives (i.e. clauses of the type I made him send a letter to the editor), the beneficiary or recipient in the effected event gets assigned indirect object case, and the causee moves down to other oblique. 
Comrie's account works rather well for a large number of languages. Particularly well supported by cross-linguistic evidence is the portion of the hierarchy that predicts that causees of ICs are coded as direct objects and causees of TCs as indirect objects. The Basque data in (2) illustrate this pattern, as do the well-known French examples in (3):
a. J'ai fait courir Paul.
I-have made run Paul
'I made Paul run.'
b. J'ai fait manger les pommes à Paul. I-have made eat the apples to Paul 'I made Paul eat the apples.'

Case-marking generalizations such as those observed so far cut across both morphological and analytic causatives. In fact, most of Comrie's examples are from languages with morphological causatives as their primary causative-forming structure.

Comrie is very thorough in noting where his account encounters difficulties, and offers various supplemental accounts. One difficulty that is particularly relevant to our discussion is the following: non-dative oblique case marking, for example cases used to express an instrument, is often found on the causee of a TC instead of dative marking, although the hierarchy predicts dative case. Example (4) from Finnish shows this. In Finnish, it is impossible to use the dative for the causee of a TC.

\section{(4) Minä rakennutin talo-n muurarei-lla. \\ I build.CAUS house-DO bricklayers-INSTR \\ 'I make the bricklayers build the house.' (Comrie 1976: 273)}

A second problem is that there is a very widespread possibility for variation in case marking on the causee in TCs. The hierarchy by itself would not lead us to expect any variation. Furthermore, that variation is accompanied by semantic differentiation between the different possible case markings. Again, this is unaccounted for by the formal hierarchy alone; supplemental principles would be required to account for such differentiation.

From our point of view, variation in case marking that is associated with semantic principles is a clear indication that the meanings of the case markers are involved, rather than a purely formal hierarchy. As we will show, there are general principles that govern the semantic differentiations associated with the case marking in causatives. Ideally, one should have a single account that incorporates both the cross-linguistic distribution of cases and the generalizations regarding semantic differentiation 
that have been observed. ${ }^{12}$ In the following section we propose such an account.

\section{Analysis}

Instead of considering case marking in causative structures in terms of a case hierarchy, we propose to relate it to the case marking found in noncausative, simple clauses. Where there are semantic differences between differently marked causees, we examine such differences for further clues to the relation between simple and causative clauses. We will first present our hypotheses, based on the facts presented so far, and then go on to justify them.

\subsection{Causative clauses as elaborations of simple clauses}

First of all, we propose that ICs show subject and direct object marking on their principal participants, just like a simple transitive clause, because they take the simple transitive clause as a structural and conceptual model. In other words, clauses of the pattern $I$ ate the cake are the pattern for clauses of the type I made Terry cry.

Secondly, the case marking patterns in TCs noted by Comrie are of two basic types, parallel to two kinds of simple clauses. In some languages, the TC structure is modelled on the structure of a ditransitive clause (subject, object, and indirect object marking on the three participants). Thus, clauses of the type I gave her the apple are used in some languages as a basic template for more complex causative structures of the type I made John do it. In other languages, for example Finnish, the model for TCs is provided by sentences of the type: I hit it with a hammer (cf. the Finnish example in (4) above; another language of this type is Yidiny-cf. Dixon 1977). Some languages allow for more than one possibility; we will consider such cases in section 4.2 below. ${ }^{13}$

The correspondences described above between causative and simple clause types are summed up in Figure 1.

One possible reservation that could be pointed out is that the semantic roles of the corresponding nominal participants, as indicated in Figure 1, simply do not match up. In sentences like I made Terry cry, although it is true that Terry may be patient-like in some respects, the participant also has some degree of initiative capacity, as animate subjects of intransitives usually do. Another obvious difference between the transitive and the causative constructions is the fact that transitive clauses contain a single verbal predicate, while causative structures have two predicates.

On the other hand, when we consider the semantic analysis of transitive clause structures as proposed in, for example, Givón (1984), Rice (1987), 


\begin{tabular}{|llll|}
\hline Simple Transitive Clause: & Agent & Patient & $\mathrm{V}_{\mathrm{t}}$ \\
IC Clause: & Causer & Causee & {$\left[\mathrm{V}_{\text {caus }}^{\mid} \mathrm{V}_{\mathrm{i}}\right]$} \\
\hline
\end{tabular}

\begin{tabular}{llll|}
\hline Simple 3-Participant Clause: & Agent & Dative/Instrumental & Patient \\
TC Clause: & $\left.\right|_{\text {Causer }} ^{\mid}$ & Causee & $\mathrm{V}_{3}$ \\
$\mathrm{~V}_{\mathrm{i}} \quad=$ Intransitive Verb & $\mathrm{V}_{\mathrm{t}}=$ Transitive Verb & $\left.\mathrm{V}_{\text {caus }} \mathrm{V}_{\mathrm{t}}\right]$ \\
$\mathrm{V}_{\text {caus }}=$ Causative Verb & $\mathrm{V}_{3}=$ 3-Participant Verb
\end{tabular}

Figure 1. Correspondence between simple and causative clauses

and Langacker (1991), the relation between the two types does not seem so distant. Givón proposed what he called the "prototypical transitive event" based on a set of semantic parameters demonstrated by Hopper and Thompson (1980) to affect the formal marking of transitivity in the languages of the world. Givón's prototype was not an unstructured list or feature bundle but rather an integrated conception that was claimed to underlie the grammatical category of transitivity in human language. As such, it was an example of what Lakoff (1987 and elsewhere) terms a "cognitive model", a mode of structuring perceived reality in a relatively idealized way.

Rice (1987) interpreted Hopper and Thompson's findings as evidence of strong prototype effects associated with the grammatical category of transitivity, and demonstrated a range of other such effects. As such, her findings supported the claim that basic clause structure types were grounded in cognitive models, presumably based on conceptually important "scenes" (cf. Fillmore 1977).

The following is a brief description of the prototypical transitive (or two-participant) event (see the references cited above for more discussion): it has an agentive participant, that is, a highly individuated entity capable of volition, and volitionally exerting physical energy on a second participant, which is also a highly individuated participant. This participant absorbs the energy, whereby it undergoes a change of state that would not have taken place without the exertion of energy. The effect on the second participant is direct, that is, there are no observed intermediaries such as a third participant: the effect is complete; there is physical contact between the two participants; and this contact is seen as giving rise to the change of state.

The formal correlate of this type of conceived situation is a clause with 
a single verb of physical transmission of energy, which is understood to have two participants associated with it, often expressed by noun phrases.

The causative of intransitive, we claim, has a prototype that is very similar to the transitive event prototype. In both cases, one participant is the conceived source or initiator of the event as a whole, and there is a second participant, an entity that is primarily affected, rather than causing. Some linguists, such as Delancey (1984) and Croft (1991), very explicitly identify the conceptual basis of transitivity as causal. In our view, the transitive event does involve causality prototypically, but this conceptual/linguistic prototype is extended, in language-particular ways, to a transitive schema involving an abstract analog of physical force. In this sense we think of transitivity as essentially force-dynamic in nature, and the intransitive causative schema preserves this force-dynamic structure.

The most obvious differences between the two construction types are the following: first, in the IC the causation is broken down into two aspects, causation itself, and then a more specific caused event involving the causee, as described in section 2 . In addition, the IC prototypically involves a less direct or to some degree mediated causation than the transitive construction. This difference between the transitive and the causative has been established in the causatives literature by showing the contrast in many languages (which, following Haiman 1983, we claim to be universal) between lexical causatives and analyzable causative constructions (cf. section 2).

The two event types, simple transitive and intransitive causative, therefore share more than simply the formal property of involving two syntactic arguments. The function of the intransitive causative structure is to express a situation in which one participant exerts force, or some abstract analog of force, on another entity. It is this similarity, we claim, that provides the motivation for the commonest cross-linguistic pattern, namely that in which the causee is treated as a direct object.

We can also note that there is frequently a diachronic path between certain morphological causative structures and transitive verbs: old causative markers, specifically those primarily expressing physical causation, are not infrequently absorbed and become unanalyzable parts of certain verb roots they occur in construction with. For example English set and lay are transitive verbs that formerly had observable causative morphemes in them. Matisoff (1976) documents numerous such fossil causatives for Lahu; the absorption of a causative morpheme so that it is no longer analyzable as such is not an unusual historical process. This recurrent diachronic pathway, in our interpretation, is another indication of semantic relatedness of causatives and transitive verbs. Transitive verbs express- 
ing causation, of course, express maximally direct causation, which is prototypically direct physical causation, so it is not surprising that this diachronic development tends to occur in those cases where the [verb + causative] complex indicates physical causation.

The argument we are making is not that transitives are "really" causative in nature but that causative conceptual structures are semantically enough like transitive structures, particularly the prototype conceptual structures associated with those structures, to make the simpler construction, the transitive clause, a good basis for extension for the more complex construction.

The nature of the notion of "extension" invoked here deserves more explication than we can devote to it in the present paper; but a few words of clarification are in order. What we have in mind is not simply a diachronic spread of aspects of one structure to the other, but an asymmetric synchronic relation between two structures that are similar in specifiable respects, in which one structure is the more basic, among other things, by virtue of being less complex. The relation between the structures can be viewed as one of inheritance of particular properties from the more basic one by the more complex one. This type of paradigmatic relation is similar, if not identical, to one identified by Lakoff (1987: Case Study 3) as the "based-on" relation, which, as he demonstrates, enables the precise statement of relations among similar constructions. See also Goldberg (1992) for use of the "based-on" relation in the description of a family of English constructions. ${ }^{14}$

It is clear that IC constructions, both within and across languages, differ as to how closely the IC structure formally approximates the transitive. Some structures may display a greater similarity to the transitive structure than others, and we might expect that over time there would be diachronic drift of semantically appropriate causative structures (e.g. those associated with relatively more direct causation) towards the form of transitive structures, with ever greater degrees of formal fusion.

Turning to the three participant structures, again we find a semantic similarity between the prototypes of the non-causative and causative structures. Common ditransitive predicates like GIVE, PUT, SHOW, and so forth all intuitively involve the idea of an agent causing something to happen, for example, causing an entity to come into possession of something, causing an entity to be located somewhere, causing an entity to come into view, etc. The fact that the most prototypical ditransitive verbs are lexical causatives suggests that the semantic prototype associated with ditransitive structures also involves some notion of causation, like the transitive prototype..$^{15}$

In Dutch, the ordinary way of saying "show" is laten zien, a causative 
structure that literally means 'let see'. It happens that this verb is an analyzable complex predicate instead of a simplex like other ditransitive verbs in the language, and like its closest semantic equivalents in English and other languages with unanalyzable predicates for "show". It is not unusual to find examples of causative structures that are obligatorily used for notions which in other languages are expressed in a simple ditransitive predicate. In Ainu, even the concept 'give', in most languages expressed as a verb in a ditransitive structure, is expressed as a causative of a verb of possession: kor 'have' vs. kor-e (have + CAUS) 'give', literally 'make have'.

In some languages, the causative marker is synchronically or diachronically the word for 'give' (e.g. Luo miyo) ${ }^{16}$ This suggests that the participants of the causative structure are recurrently seen as analogous to the participants of a ditransitive clause.

As to the semantic role mismatch alluded to above between causee and the participant expressed by the indirect object in a ditransitive construction, we observe that indeed the causee in the TC construction is certainly not the same as a recipient or beneficiary, the prototypical semantic roles associated with indirect objects. Although we are not dealing with the same semantic role from the point of view of the sentences as a whole, we nevertheless argue that there are fundamental similarities between the two participants which motivate the similarity of marking. There is, for example, a clear semantic affinity between causee and indirect object in terms of animacy: the most typical causees are animate, just like indirect objects. But in addition, as we will see in sections 4.2 and 4.4, there are more specific similarities between recipients/ beneficiaries on the one hand, and the causee in TC structures: for one thing, the experiencer-like properties of each of these participant types, which motivates the dative marking found in their expression.

We do not wish to claim that the causee participant in a transitive causative structure is a "kind" of recipient or benefactive, but rather that it is semantically similar to dative case roles in crucial respects, such that dative markers can by semantic extension mark causees as well. ${ }^{17}$

As to the relation of the instrumental construction of the type Mary cut the cake with a knife, similar considerations hold. The overarching schematic notion shared by both instruments and causees in TCs is that they are causal intermediaries on the path of energy flow elaborated by the clause. In this case, there is a difference in animacy between the corresponding participants: a prototypical instrument is inanimate, while a prototypical causee is animate. However, an animate entity can be viewed as a kind of metaphorical instrument, employed by the causer to get an action carried out. 
Some languages distinguish between types of instruments, or causal intermediaries: for example, French distinguishes marking of simple physical instruments from marking of more abstract means (avec vs. par; cf. Elle a prouvé ça par des exemples 'She has proven that by means of examples'. We consider such means-instrument constructions to fall under the rubric of an instrumental clause type and expect that the semantics of the specific instrumental marker in a given language will figure in the relation of the simple and the TC causative clause types. The semantic relation between instruments and instrument-marked causees will be fleshed out in more detail in sections 4.2 and 4.4.

The causee in a TC construction, whether dative or instrumental, shares with its simple clause counterparts the property of being in some sense a "third" participant, less crucial to the structure of the event as a whole than the subject and direct object, which are conceptually the core participants in the event (cf. Fillmore 1977). If we can assume that the causee of a TC in a clause is conceptually less integral to the event than the other two participants, we can understand why causees tend to be dispensible: as noted by Nedjalkov and Sil'nickij (1973), if one of the participants of the TC is missing, it is almost always the causee. Similarly, there are relatively few verbs in any given language that require a recipient, and benefactives and instruments are cross-linguistically "extra" participants that can be added optionally. These facts suggest a semantic property shared between the TC causee and the oblique participants in simple clauses, namely their relative peripherality in the clausal prediction. ${ }^{18}$ As we will see below, instrumental-marked causees are more peripheral in the overall event structure than dative-marked ones.

Now although, as we claim, the causee in TCs is conceptually less integral to an event of causation than the causer and affectee, it is important to note that it is still a participant that directly interacts with the other two at the level of the causal event as a whole, just as indirect objects and instruments interact directly as participants with respect to a simple predicate. The direct interaction of the CAUSER, CAUSEE, and AFFECTEE in a single conceptual event structure is, in our view, what motivates the single-clause properties of causative constructions in ail languages that formally distinguish single clause from biclausal structures.

We have now presented the thrust of our analysis of the structure of causative clauses. We will go on to demonstrate that this account provides a natural framework for the analysis of observed semantic differentiations between case markings in causative clauses. The occurrences of particular case markers in causative constructions cross-linguistically, and the recurrent semantic differentiations found to be associated with them, will be 
shown to follow without the necessity for a purely formal case hierarchy, or other (non-semantic) principles of "case assignment".

\subsection{Semantic differentiations}

Case marking in ICs is generally straightforward, in that languages tend to have only one possibility for case marking on the causee. The causee in TCs, on the other hand, frequently allows for more than one case marking possibility. We begin by considering alternations between instrument marking and other case markings, specifically direct or indirect object (or language-specific exponents of these such as accusative and dative). It turns out that the semantic differences found shed a good deal of light on the nature of causees in TC constructions and how these causees relate to participants in simple clauses like recipients and instruments.

Some revealing examples from Hindi are cited in Saksena (1980). In Hindi, there are a few verbs that allow alternation in TC constructions between dative and instrumental marking. (We will return to the issue of the dative vs. instrumental contrast in Hindi causative constructions in general below.) Where this alternation exists, we find a regular meaning contrast. Consider the examples in (5).

\section{(5) a. Mai-nee raam-koo kitaab parh-vaa-ii.}

I-AGT Ram-DAT book read-CAUS-PAST(f.)

'I had Ram read the book.'

b. Mai-nee raam-see kitaab parh-vaa-ii.

I-AGT Ram-INST book read-CAUS-PAST(f.)

'I had Ram read the book.' (Saksena's translation; cf. below)

In (5a), Ram occurs with dative marking; the sentence would be used in cases in which the aim is to get Ram to read the book. With instrumental marking, as in (5b), however, the sentence means something different: in this case, the aim is to get the book read. In other words, with instrumental case marking, the causee is not topical, while with dative marking, it is. Given Saksena's description of the semantic difference, a better translation than that given might therefore be something like ' $\mathrm{I}$ had the book read by Ram'.

The examples in (6) indicate a similar contrast.

a. Mai-nee raam-koo masaalaa cakh-vaa-yaa.

I-AGT Ram-DAT spice taste-CAUS-PAST

'I had Ram taste the seasoning.' 
b. Mai-nee raam-see masaalaa cakh-vaa-yaa. I-AGT Ram-INST spice taste-CAUS-PAST 'I had Ram taste the seasoning.' (Saksena's translation)

With dative marking, the interpretation is that the tasting is for Ram's benefit; with instrumental, the tasting is for the benefit of someone else, for example the cook, or perhaps a king who must have his food tasted. We can interpret the sentence as something like the following: 'I got the seasoning tasted by asking Ram to do it.' Here again, a topical vs. nontopical contrast is evident, with the dative case marking the more topical participant, and the instrumental the less topical. Hyman and Zimmer (1976: 198, examples 32-33) report an entirely parallel contrast between dative and instrumental in French. ${ }^{19}$

Let us now consider some similar contrasts involving other cases. The German examples in (7), cited in Comrie (1976: 300-301), show an alternation between an accusative-marked causee, and a causee marked with von, the dative-governing preposition that also occurs with passive agents (we will call this "agentive" and discuss the connection between causees and passive agents below) ${ }^{20}$
a. Er liess seinen Sohn den Brief abtippen.
He let his.ACC son the letter offtype
'He made his son type the letter.'
b. Er liess den Brief von seinem Sohn abtippen.
He let the.ACC letter by his.DAT son offtype
'He had the letter typed by his son.'

Here again a difference in topicality is evident: in (7a) we are dealing with discussion of the son, while in $(7 \mathrm{~b})$ the discussion concerns the letter. There is an additional factor differentiating these two sentences, namely direct vs. indirect causation (i.e. more direct vs. more mediated causation;. cf. section 2), to which we will return below.

A third case of alternation, cited in Cole (1983: 120), is found in Kannada:
a.
Avanu
nanage bisketannu tinnisidanu.
he.NOM I.DAT biscuit eat.CAUS
'He fed me a biscuit.'
b. Avanu nanninda bisketannu tinnisidanu. he.NOM I.INSTR biscuit eat.CAUS 'He got me to eat the biscuit.'

Here, the meaning distinction reported is a contrast between direct vs. indirect causation, where the dative represents a participant who is much 
more of a passive recipient of the action (e.g. a small child), while the instrumental marks a participant who is being induced to do something within his/her own power, i.e. someone who has more autonomy of action. (For simplicity's sake, we refer to this difference in relative directness of causation as one of direct vs. indirect causation, as described in section 2 , with the reminder that maximally direct causation is associated with lexical causatives.)

There are many other cases of languages in which the instrumental is associated with more indirect causation in contrast to dative or accusative case marking, for example Hungarian (Hetzron 1976). In the German case above, the contrast is between agentive and accusative, rather than instrumental and dative, but a parallel semantic differentiation exists. In addition to the topical vs. non-topical contrast discussed above, we also find that the agentive case in German expresses more indirect causation in comparison with the accusative; the latter expresses direct causation, here, causation that is conceived as relatively unmediated. In (7a) the implication is that the son is working under direct orders from the father, not communicated through anyone else; thus he has a relatively low degree of autonomy and is subject to more direct control. In (7b), the son is not only viewed as less important in the process of getting the letter typed than in (7a), but is also possessed of more autonomy of action. Furthermore, with the utterance of $(7 \mathrm{~b})$ there is a greater possibility of physical distance between the participants and of lack of direct verbal contact between them, factors also reflective of more mediated causation.

Presumably, any of these factors (lack of conceived importance in effecting the letter's typing, autonomy, physical distance, lack of direct verbal contact) holding of a given conceived situation can contribute to the use of the von construction to code the causee rather than accusative case. We might predict that the more of such factors that hold, the more likely or felicitous will be the coding with von.

Directness vs. indirectness of causation, we might notice, is closely related to the issue of which participant is more topical: the more indirect the causation, the more peripheral a participant the causee is, and peripherality normally would not cohere with topicality. ${ }^{21}$

It also relates to which participant is viewed as more affected: the more affected the participant, the more object-like and therefore central it is to the event as a whole. Thus agentive and instrumental marking (which may in some languages be the same marking) are consistently associated with more peripheral participants, which have more control over their actions and are less directly affected, while dative and accusative participants are more central participants with less independence of action and 
a greater degree of conceived affectedness. The dative is intermediate in terms of these properties, while the accusative is the polar opposite to the instrumental and/or agentive. ${ }^{22}$

An example of an accusative/dative opposition in TCs exists in French (at least for some speakers, and only in pronominal causees-Hyman and Zimmer 1976: 193-194). According to Hyman and Zimmer, the causation is interpreted to be more direct and the causee is interpreted to be more affected against his will when the causee is marked accusative than when it is marked dative. Thus, Je l' $[A C C]$ ai fait manger des épinards means that the causee is forced to eat spinach against his will, while Je lui [DAT] ai fait manger des épinards means that I fed him spinach, for example because he was hungry. It is clear that this pattern conforms to our general analysis.

The semantic opposition between more vs. less directly affected participants, as is well known, is a determining factor in accusative vs. oblique (viz. dative or instrumental) case marking contrasts in simple clauses in many languages (cf. Anderson 1970; Kirsner et al. 1985). We interpret this fact as another indication that the participants in simple clauses differ from one another in terms of degree of integration in the event as a whole. We would therefore expect that in some languages accusative vs. oblique contrasts would be found not only in simple clauses but in causative clauses as well. The German example in (7) and the French examples cited above represent such cases.

As mentioned above, languages tend to have only one possibility for case marking of the causee in ICs, probably due to the general tendency for simpler structures to exhibit greater degrees of grammaticization of structure (e.g. less choice) than more complex structures. However, alternations are attested for causees in ICs in Japanese (accusative vs. dative/instrumental; cf. Shibatani 1973) and Hungarian (accusative vs. instrumental; cf. Hetzron 1976), and semantic differentiations run parallel to those found in TCs in other languages.

It is worth considering in more detail at this point the Hindi case described above so that we can see how the larger pattern of dative and instrumental case marking in the language fits with the generalizations we have been discussing here. In Hindi, ICs typically have dative-marked causees. Dative is the case found also on animate direct objects, as noted below. Causees in TCs, on the other hand, are typically marked instrumental. Only a few verbs allow dative marking in addition to the possibility of instrumental marking, including the cases illustrated above in (5) and (6).

Saksena (1980) interprets the difference between dative and instrumental as due to a difference in degree of affectedness of the causee: the 
dative signals greater affectedness, the instrumental less. We essentially agree with this formulation. In our account, unlike in Saksena's, however, the difference in affectedness follows from the semantics of the various case roles as described above. Dative-marked participants, as we have seen, are those which are affected as humans are affected, viz. experientially. With instrumental participants, on the other hand, the focus is not on the experiencing of an effect by the participant but on nothing more than its intermediary role in accomplishing the effected event. Dative participants are experientially affected, instrumentals are not. Experiential affectedness correlates with a greater degree of integration into the event than is found with instrumental participants.

There is some additional evidence that the notion of experience is indeed relevant in cases such as these. The use of the dative, in Hindi as well as in a number of other languages (e.g. Dutch, Kannada, and Quechua; cf. Cole 1983) is restricted to a limited set of predicates, specifically those that can be construed as experiences on the part of the causee (e.g. "see", "read", "hear", "notice"). Though there is certainly more that could be said about this restriction, it is noteworthy that it recurs in unrelated languages: when a language allows for both dative and instrumental marking of the causee in a TC, the dative consistently gets associated with experiential causees.

To sum up the Hindi situation, we can say that in causative constructions as a whole, instrumental and dative case marking are found on different causative structures with overall differences in degree of integration of the causee into the event: the causees in ICs, being the most patient-like participants in the clause, are highly integrated and hence are unmarked (inanimate patients) or dative-marked (animate patients), while those in TCs, where there is an affectee, are less integrated. In the few cases where the language permits the two oblique cases to contrast directly, as in examples (5) and (6) above, the semantic differences follow the same pattern of DATIVE = more integrated, highly topical participant, affected as a human entity, vs. INSTRUMENTAL = low degree of integration into event, low topicality, low degree of affectedness.

The non-topicality/peripherality of the non-dative oblique participants described above makes it unsurprising that languages frequently use the same case on causees of TCs as they use on passive agents: passive agents are also rather nontopical, fairly dispensible participants. If the agent were topical, of course, one would not use a passive construction at all. This agentive case is in some languages the same marking as instrumental, and in others the same marking as other oblique cases.

Thus, instances of non-dative, oblique-marked causees are readily interpretable in our framework. They are a notable difficulty for the Comrie 
hierarchy discussed in section 3, because they "skip over" the predicted dative. The fact that such causees are often marked with the same case as passive agents leads Comrie to offer the suggestion that agentive marking appears on the causee in these cases because some mechanism of passivization has applied before causativization (cf. also Hyman and Zimmer 1976 on French). He acknowledges the problems with this analysis, including the following: (1) there is never any passive morphology on the verb in these constructions; and (2) there are cases like Finnish, illustrated in (4) above, that use instrumental case but do not allow agentive passive constructions.

In our view, it is more reasonable to say that the agentive marking on the causees is motivated by the semantics of such markers. Where the marking is the same as that found on instruments (whether physical instruments or more abstract means arguments, as in French par and Dutch door), we can say that the marking found on instruments, passive agents, and the similarly marked causees designates a dispensible, nontopical causal intermediary. ${ }^{23}$ Where the marking found on causees and passive agents excludes (prototypical) instruments, then the marker incorporates the just-mentioned specification in its semantics, but in addition specifies agentivity. In either case, the causee represents a participant that is not prominent in any way in the overall conceptualization of the event. These participants are causees that can easily be left unexpressed.

The generalizations drawn above are strongly supported by evidence from Dutch. This language is interesting in that it has in certain limited cases a three-way contrast in case-marking possibilities on the causee: zero (on full noun phrases; personal pronouns appear in non-nominative form like pronominal direct objects in general) vs. prepositional dative vs. agentive/instrumental marking. The normal contrast is between zero and agentive/instrumental case-marking (the preposition door); the dative (expressed by the preposition aan) is fairly restricted. But with the verb lezen 'to read', all three markings are possible, as illustrated in (9).

(9) a. Hij liet haar de brief lezen. ( $\phi /$ non-nom.PN)

He let her the letter read

'He let/had her read the letter.'

b. Hij liet de brief aan iedereen lezen. (DAT)

He let the letter to everybody read

'He let/had everybody read the letter.'

c. He liet de brief door iemand lezen. (AGENTIVE/INST)

He let the letter by somebody read

'He had the letter read by somebody.' 
As we might expect from our discussion above, there are semantic contrasts associated with these different forms. With the agentive/instrumental case exemplified in (9c), the letter is clearly the topic of discussion; as a metaphorical instrument, the actual reader is just of incidental importance. There is also the suggestion that the reading is done for a purpose like checking grammar and spelling, or for some implied audience who are listening to an oral delivery (the purpose of the reading then is delivery of the letter to those hearers). In neither case does the meaning involve a reading for content on the part of the actual reader.

With the dative (9b), however, reading for content is exactly the interpretation we find: 'He let everybody read the letter so that they could find out what it said.' This interpretation fits with the idea of the dative as the case used for participants affected as people are affected, mentally rather than purely physically. (Hyman and Zimmer [1976: 206, example 50] describe an exactly parallel contrast in French with the verb lire 'read'.)

With no prepositional marking (9a), the interpretation is somewhat similar to that with dative marking, in that the reading is for content. But there is a distinction between the two; in fact, the same distinction as we find between zero-marked and dative-marked indirect objects in simple clauses (cf. Kirsner 1988): zero-marked indirect objects are more topical than dative-marked ones, as evidenced by the fact that in discourse they are most likely to be personal pronouns, while the dative-marked ones are most likely to be full noun phrases, and indeed indefinite, hence non-topical, noun phrases. ${ }^{24}$

Thus the rather intricate details of Dutch show the same general correlation of greatest integration with non-oblique participants and progressively less integration with dative and agentive/instrumental.

A summary of the variations in case marking on the causee in TCs in a number of languages is given in (10):

(10) Variation in case marking on causee of transitive causative:

Dutch $\quad \varnothing \sim$ Dative $\sim$ Agentive/Instrumental

French Dative $\sim$ Agentive/Instrumental

German Accusative $\sim$ Agentive/Instrumental

Hindi Dative $\sim$ Instrumental

Kannada Dative $\sim$ Instrumental

Mongolian Dative (= Agentive) Instrumental

Quechua Accusative $\sim$ Dative $\sim$ Instrumental

Our claim is that case-marked participants in general differ in degree of conceptual integration in the clausal event, with accusative most integ- 
rated, dative less integrated, and instrumental and/or agentive least integrated, where high degree of integration correlates with high degree of affectedness and topicality and low degree of autonomy of the causee. We predict that, if a language allows causees with different case marking in a given causative construction (IC or TC), those causee participants will be semantically distinguished in terms of degree of integration following the generalizations summarized in the preceding sentence.

Considering the overall relation between ICs and TCs in terms of the participants evoked by the constructions, we predict that causees in ICs are most likely, cross-linguistically, to occur with accusative (or direct object) case marking, as in the basic transitive clause schema which forms their structural and conceptual model. Many languages will grammaticize this pattern as the strongly preferred or even the only possibility for marking of the causee. In TCs, we predict that causees are most likely to occur with oblique (dative or instrumental) case marking, the case markings associated with tertiary participants, since causees in these constructions are semantic extensions, along specific parameters, from tertiary participants in simple clauses. Again, we expect to find some languages in which a particular oblique case has been grammaticized, either as the only possibility or as a strongly preferred option.

Even in cases of maximal grammaticization, i.e. virtually no options in expression of the causee, we claim that the case marking in causative constructions is semantically motivated, as evidenced by the overall contrast between the marking of causees in ICs and TCs, and the semantic relations between causees and participants in simple clauses as described above. ${ }^{25}$

In our view, the case hierarchy, rather than a purely formal set of relations, represents a semantically-based set of relations among participant types. These relations are based on the functions of the participants they mark within a few basic cognitive models, i.e. integrated event structures. The most prototypical values of the cases are associated with the basic simple clause models; the function of the case markers in causative constructions represents extended values of these markers. Each case marker has a schema associated with it that represents its semantically most schematic value, subsuming the more specific usage types it expresses.

Our account, lacking the purely formal stipulation that one must "move down" the hierarchy in step-by-step fashion, readily assimilates languages in which dative case marking is not an option. Our framework also naturally accommodates causeeless causative expressions of the type exemplified by Dutch Zij laten een huis bouwen 'They are having a house built', which Comrie's account does not incorporate. In our view, causee- 
less causatives constitute the extreme case of peripherality of the causee participant: here, rather than being elaborated in the clause with specific semantic content, the causee remains entirely schematic and is simply not expressed. ${ }^{26}$

To sum up our argument so far, we assert that it is the relation of the various participants in a causative event to one another and to the overarching causative event which is most important in the structure of causatives, rather than the specific semantic roles filled by the participants with respect to the effected or causal predicates. The similarity of causative constructions to simple clauses lies in the conceptual structure of direct interaction of participants in the event and the fact that the participants differ in terms of their degree and mode of integration in the event as a whole.

Language-specific similarities between corresponding clause types relate to the particular case markings selected to express the causee. The possibilities are constrained by the semantics of the markers in simple clauses and by linguistic convention, i.e. which markers have become grammaticized in a particular function. These two factors are, of course, related, since possible conventionalizations are themselves constrained by the semantics of the markers in more basic uses, i.e. in simple clauses (cf. Bybee and Pagliuca 1987 and elsewhere).

Cross-linguistic variation in causative constructions, in our view, is governed by two principal factors: first, the extensions particular case markers have undergone (which is highly constrained, as mentioned above); and secondly, the degree to which each causative construction has assimilated to its simple structural/conceptual model. Causative structures can become more like their basic-clause counterparts over time, for example in showing increasing properties of "monoclausality" (cf. the discussion of the history of French faire in Hyman and Zimmer 1976; see also Givón 1975).

\subsection{Further relations of causative to simple clause structures}

We would like to mention some additional evidence for the relations we posit among the various clause types discussed. This evidence comes from some telling formal relations of causative structures with other threeparticipant structures outside the realm of case marking. Specifically, we refer to verb extensions of the type that have been called "valency increasers".

Examples (11a) and (11b) are from Wolof, cited in Comrie (1981: 176).

(11) a. Di naa toog-al nenne bi FUT 1.SG sit-CAUS child the 'I will make the child sit.' 

b. Mungi dyàng-al eleew yi tééé-ém he read-DITR pupil the-PL book-his 'He is reading his book to the pupils.'

We have glossed the form -al differently in the two examples in the spirit of Comrie, who does not consider the marker in the two cases to have the same meaning. Comrie's claim is essentially that nothing about the semantics of causatives and ditransitive constructions like (11b) would lead to the similar marking we find: only the formal property of "increased valency" motivates this connection. But, as argued in sections 4.1 and 4.2 in relation to case marking facts, there are more semantic similarities between causatives and simple clause structures (including ditransitives) than have been acknowledged, and these can be understood to motivate the similar marking. The use of the identical verbal marker is perfectly understandable if causatives are viewed as complex, twopredicate extensions of simple clauses.

A parallel piece of evidence can be cited in relation to instrumental markers. For example, in Kinyarwanda we find a connection between the marker that indicates that the verb takes an instrument in a simple clause, and the causative marker. This is illustrated in (12). A similar pattern is found in a number of other languages.
a. Umugabo a-ra-andik-iiš-a ikárámu íbárúwa man 3SG-PRES-write-INST-ASP pen letter 'The man is writing a letter with a pen.'
b. Umugabo a-ra-andik-iiš-a man 3SG-PRES-write-CAUS-ASP man letter 'The man is making the man write a letter.'

Again, we have glossed the marker $i i{ }^{2}$ differently in each case, but it is clear in the light of the foregoing discussion that we want to consider them the same morpheme. The similarity in form of the two markers is not a coincidence, nor is it simply a result of a purely syntactic process of "valency increase": the same marker is used because creating a TC structure is analogous in crucial respects to creating an instrumental structure.

Finally, Tuggy (1988) describes the polysemy of the applicative verbal suffix in Nahuatl, which also serves as a causative marker. Tuggy's analysis suggests that this language instantiates yet another possibility for a causative structure to be based on a simple three-participant event, this time a verbal benefactive construction. 
4.4. Degree of integration and the semantics of causative verbs: Evidence from Dutch

As a final piece of evidence in support of our overall claims, we would like to consider some data from Dutch that have not previously figured in discussions of case marking of causees. Dutch has two analytic causative constructions with different verbs designating the causal predicate (we will refer to such verbs as causative verbs). We will show that the lexical semantics of causative verbs in this language affects the choice of case marking in a way entirely parallel to the situation we observed in connection with examples (5)-(9) in section 4.2. We argued there that one aspect of integration that can affect case-marking choice is directness vs. indirectness of causation.

Dutch distinguishes between more direct and less direct causation by means of a choice in causal predicate. Besides laten 'to let', exemplified in (9) above, there is another causative verb doen 'to do, to make', which explicitly signals direct causation. An example is given in (13): ${ }^{27}$

(13) Wij zullen de reorganisatie gefaseerd doen plaatsvinden.

We will the reorganization in-phases do take-place

'We will make/have the reorganization take place in stages.'

Here, $W i j$ 'we', refers to the government, and the use of doen rather than laten indicates that the government has (at least in its own opinion) direct control over the way the reorganization will take place. ${ }^{28}$

The choice between doen and laten strongly influences the case-marking possibilities for causees: in other words, it has strong effects in the area that the formal case hierarchy was designed to handle. The data in (14) summarize percentages of the use of the various case markings found in causative structures, both ICs and TCs, that have a causee expressed (approximately two-thirds of the total number of causative sentences in our corpus). For each causative verb, both the raw number of examples (in parentheses) and the percentage of causees used with that predicate and marked with the specified case marking are given, as well as one or two examples to illustrate the use of the marking with the verb in question.

(14) Case marking on causee:

a. In causatives of intransitives (417): $100 \% \varnothing$-marking (with both laten and doen)

b. In causatives of transitives (143):

-with laten (118):

$47 \% \varnothing$-marking (including non-nominative personal PN): 
$U$ kunt ook uw man de boodschappen laten doen. You can also your husband the groceries let do 'You can also have your husband get the groceries.'

6\% DAT-marking:

Hij wilde het aan een collega laten zien.

He wanted it to a colleague let see

'He wanted to show it to a colleague.'

$47 \%$ AG/INST-marking

Zij lieten Woody adopteren door een echtpaar.

They let Woody adopt by a married-couple

'They had Woody adopted by a married couple.'

一with doen (25): 100\% $\varnothing$-marking (including

non-nominative personal PN):

Dit deed de VPRO leden verliezen.

This did the VPRO members lose

'This made the VPRO lose members.'

De stralende zon doet de temperatuur oplopen.

The radiant sun does the temperature rise

'The bright sun makes the temperature rise.'

The first thing to note is that with ICs we find only zero marking, both with laten and doen. In this respect the IC structure mirrors the simple transitive clause structure: in Dutch, simple transitives do not allow different possibilities for case marking on the patient. Rather striking differences show up, however, with TCs. With laten, we find large proportions of causees with zero marking and with agentive/instrumental marking (both $47 \%$ ), and a limited number with dative marking. But with doen, we find only zero marking. No formal hierarchy, as far as we can see, will be able to explain such a difference, for a formal hierarchy of case roles or grammatical relations is not sensitive to the semantics involved in the choice of causal predicate. We claim that it is precisely the semantic difference between doen and laten that affects the choice of case-marking, as we will now show.

Some typical instances of doen-causatives are given in the final two examples in (14). In the first of these, some event denoted by Dit 'this' caused an association named VPRO to lose members. The second example is about the sun causing the temperature to rise. Note that both sentences are not about human interaction, i.e. not about two animate beings engaged in some activity involving communication, such that one (the causer) ultimately effects something in the mind or behavior of the 
other. We conceive of the latter, i.e. interactive causal relations (cf. the notion of inducive causation in section 2), as involving indirect causation: no mind can cause a change in another mind directly. However, in the examples, the causation is indirect, for we normally conceive of the physical world (and to some extent the social world) as allowing for direct, unmediated causation, as when the sun makes the temperature rise.

The distinction between direct and indirect causation associated with the contrast between doen and laten shows up also in regard to the animacy of the participants involved. We confine ourselves here to consideration of the animacy of the causer; see Verhagen and Kemmer (1992) for discussion of animacy of the causee. The relevant percentages are shown in (15):

\section{(15) Animacy:}

laten (429): $99 \%$ animate causer; $1 \%$ inanimate causer

doen (131): $\quad 42 \%$ animate causer; $58 \%$ inanimate causer

It is clear from these data that the vast majority of laten-causers are animate, as opposed to a minority of animate causers in the case of doen. Now consider (16). ${ }^{29}$

a. De psychiater liet mij aan mijn moeder denken.

The psychiatrist let me at my mother think (indirect: communication)

'The psychiatrist made/had me think of/about by mother.'

b. De psychiater deed mij aan mijn moeder denken.

The psychiatrist did me at my mother think (direct: perception)

'The psychiatrist made me think (reminded me) of my mother.'

Example (16a), with laten, refers to the interaction of people: 'The psychiatrist told me to think of my mother and so I did.' But (16b), with doen, is not a case of human interaction at all: something in the appearance or the behavior of the psychiatrist, i.e. something observable in the outside world, reminded me of my mother. So we have here a case of perception, and as explained by D'Andrade (1987), humans conceive of perceptions as being directly caused by the outside world. The animacy of the psychiatrist is clearly not involved in this causal relation. A significant portion of the $42 \%$ of sentences with doen and an animate causer are of this kind, so that such cases in fact confirm rather than cast doubt on the claim that doen indicates direct, non-communicative causation. Another significant portion of doen examples with animate causers involve God as causer, and God is, for many speakers, the only 
being able to directly cause some effect in a person's mind, i.e. noncommunicatively. Example (17) is effectively a request for Jesus to manipulate the person's mind in the desired way (see Verhagen and Kemmer 1992 for further data and discussion):

(17) [Zij smeekte Jezus] haar de gewone weg te doen bewandelen. [She begged Jesus] her the usual road to do walk-on '[She begged Jesus] to make her walk in the usual path.'

We claim then that laten, which indicates indirect causation, leaves room, as it were, for different case-markings on the causee that express different degrees of integration in the event. The directness of causation indicated by doen, on the other hand, is responsible for the fact that doen-causees always have zero case marking. With doen, the causee is directly affected by the caused process, and as such it is central and highly integral to the event. It would therefore be inappropriate to mark it as dative or instrumental, and thus as in some way peripheral, having more autonomy of action, etc., which, as we argued in section 4.2 , is the function of these case markings.

Theoretically, one might want to argue that, while dative causees with doen should be excluded completely, instrumentals might sometimes be possible. One might imagine a causal event that is direct in the sense that the causer's action is sufficient to bring the effect about, and which therefore allows doen, but in which the causer uses some instrument; this instrument would "technically" be the causee, but it would not be viewed as autonomous, even minimally so, and thus could occur in the TC which is associated with more direct causation (the doen-causative). Such "limiting cases" do not occur in our corpus, but they might be conceivable.

In order to investigate this possibility, we constructed sentences with doen and an instrumental causee from the material in the corpus; to these we added a few examples of our own, varying the causee and the effected predicates such that they would to varying degrees allow for a "purely" instrumental reading of the causee. We asked eight informants to judge the acceptability of the sentences, both with and without instrumental marking (naturally, subjects did not know which were constructed). The results were, first, that those instrumental doen-causatives that were constructed by adding instrumental marking to actual examples were rejected unanimously; thus the correlation between actual occurrence and speakers' judgments is high. Second, the instrumental variants of most of the examples that we completely invented ourselves were also rejected. However, judgments differed strongly in the case of the following example: 
Ik heb het boek doen uitgeven door Van Dale.

I have the book do publish by Van Dale

'I had the book published by Van Dale / I had Van Dale publish the book.'

Four of our eight informants accepted this example (albeit with two of them expressing some reservations), and four rejected it. Thus, in this particular case, consensus is lacking. The nature of this case is such that the possibility of a non-affected instrumental reading of the causee is maximal: it is not a person but a company; companies are easily viewed as purely instrumental in publishing books. Apparently, this is sufficient for some, but not all, informants, when confronted with the cognitive puzzle of having to judge the sentence, to accept it. ${ }^{30}$

To sum up, there is a strong correlation between the structure of, on the one hand, the actually occurring examples and, on the other, those where informants' judgments exhibit consensus: where the data are clear, they confirm our analysis. The specific data from Dutch, then, strongly support our general semantic approach.

\section{Conclusion}

In this paper we have presented a view of causatives in which meanings of the causative structures and their components (in particular case marking and analytic causative verbs) are essential to the description and understanding of the patterns that occur. Cross-linguistic evidence suggests that there are a few basic human cognitive models of causation that involve force dynamic conceptual structures having particular configurations of participants and types of interactions among them. These models, we argued, relate to more basic models that are important in human language, notably transitive and ditransitive event structures. Languages seem to select among the semantic parameters made available in these models, and use them to construct richly detailed language-specific models that underlie the expression of causation in the language.

We would like to conclude by sketching the basics of a proposal as to how grammatical constructions should be represented. We believe they are best represented as schemas (of different degrees of specificity), some of which can be used as the basis for extension for the formation of more complex grammatical patterns. For Dutch, for example, we can posit two simple schemas, [laten $+\mathrm{V}]$ and [doen $+\mathrm{V}]$, each associated with a meaning (indirect and direct causation, respectively). These schemas are instantiated by the various combinations of laten or doen with effected predicates. The language also has transitive, ditransitive and instrumental 
clause schemas, abstracted from clauses with simple lexical predicates. Any of these clause schemas may then serve as the basis for elaboration by a clause with a complex, analyzable, causative predicate in place of the single predicate. Thus minimally more complex structures can be built up from simpler ones.

Some advantages of this approach include the following. First, it provides us with an account for the observed limitations on causatives of causatives. The limits on structural complexity result from the fact that one starts from simpler structures and builds up. The question that arises with a reduction account is: if causatives result from clausal reduction, why is it that, in general, only two-clause structures are reduced, rather than clauses of arbitrary complexity? If, however, causatives are constructed from simpler schemas, it makes sense that we find an increase in complexity of one level: the result is a more complex construction, but a construction that acts as a single clause, just like the single simple clause that forms its conceptual and structural model.

Secondly, the idea of starting from simpler structures and building up, rather than starting with complex structures and reducing, automatically has a number of implications in various domains such as text frequency, acquisition, and diachrony.

We expect that frequency of a given schema will directly correlate with the complexity of the schema: the more participants involved, the lower the frequency of the schema. In simple clauses, for example, it is known that ditransitive clauses are relatively rare in comparison with transitive ones. As we have discussed elsewhere, this is supported by analysis of frequency data in Dutch (Verhagen and Kemmer 1992; cf. also the observations in Dik 1980).

Cross-linguistically, we find that the more complex the structure, the more likely there is to be a prohibition on it (e.g. Songhai prohibits causatives of ditransitives; Mangarayi prohibits causatives of transitives). Comrie (1976) found a good deal of variation in speakers' judgements with the more complex causatives; such variation is not expected from the formal hierarchy he posits, but in our account it can naturally be interpreted as a result of the limits on complexity discussed above. We do not see such "processing factors" as independent of the grammar but as integral to understanding the variation that occurs, both in the artificial task of judging grammaticality and in language use. We might state it as a general principle that the more complex the schema, the more variability will be found in (a) the patterns that will be grammaticized across languages and (b) the willingness of informants to stretch a given schema to or past its limits.

From the point of view of acquisition, we expect ontogenetic priority 
of simpler structures over complex ones. We would expect that at least some simple predicates are learned before the first complex causative predicates appear, and that analytic causatives will be acquired before biclausal structures, in particular biclausal structures encoding causal relations, like $I$ sang for them because they asked me to. ${ }^{31}$

Diachronically, a particular causative structure bearing affinities of the sort we suggest to a given simple clause structure should come into being later than that simple structure. For example, we would expect dative markers to spread from use in the simple ditransitive construction to their use on causees in TCs, and not vice versa. Moreover, we also expect that the occurrence of particular forms in causative constructions to which they do not have a close affinity (e.g. accusative case marking on the causee in a TC construction; dative case marking on the causee in an IC construction) are the result of later diachronic spread of the form from the causative structure it more naturally "belongs" in. For example, in the dialect of Basque mentioned in note 11, in which dative marking is found on causees in both TCs and ICs, we predict that the dative in the IC construction is historically more recent than in the TC construction. This and other diachronic predictions of our account remain to be investigated.

Thirdly, viewing causative constructions as schemas in the above sense allows a unified account of causatives in languages with causative expressions that range over fixed and nonfixed expressions. For example, Dutch has a large number of idiomatic expressions based on the causative verbs laten and doen (e.g. links laten liggen 'ignore', lit. 'let lie to the left'); such expressions occur at all levels of specificity. Since these idioms display properties entirely parallel to laten and doen expressions that are not part of idioms, it is advantageous to make no qualitative distinction between idioms and "productive" causatives. ${ }^{32}$

Fourth, our schema approach suggests an explanation for why languages that have a separate case marking to express the causee are rare or nonexistent. ${ }^{33}$ This is a fact which (as far as we are aware) has not been previously noted. If, as we claim, clause schemas with simple predicates are elaborated as schemas with causative predicates, it makes sense that the case markings found in simpler structures would be those used in the more elaborated constructions. In fact, we might make the stronger prediction that the use of a case marker for a given participant in a causative clause requires there to be a corresponding simple clause structure with a similarly marked participant, relatable to the first participant both in terms of the overall participant configurations of the clause structures and the semantic specifications of the case marker itself.

Finally, it makes more sense, synchronically and diachronically, to 
view grammar as having a limited number of simple grammatical schemas that are extended to more complex conceptual material, rather than to assume a unique rule or schema for each possible construction. Our view fits with what we know of syntactic analogy, as described by the Neogrammarians and, more recently, by researchers on syntactic change (cf. Li 1977). Everything we know about syntactic change suggests that certain markings and patterns tend to get extended to syntactic contexts that were previously outside their range of application.

In short, our approach to causatives has a number of important consequences, both regarding analysis of causative expressions in particular languages, and with respect to the nature of grammatical structure in general.

We have not touched on the syntactic properties of causative structures; the syntax of causatives has, of course, been investigated in great detail, and a general account of causatives must be able to accommodate the many cross-linguistic and language-internal patterns that have been found. But a complete understanding of causatives must also take into account empirically attested semantic patternings of the type discussed in this paper, an area which has been relatively neglected in the literature so far. The fact that nonsyntactic factors were found to be highly relevant to the distribution of case marking on causees, the area in which our account has some empirical overlap with syntactic analyses, suggests that purely syntax-internal accounts of causatives might place unwarranted limits on the search for generalizations, and hence explanation.

We believe that our approach, together with an appropriate schemabased framework of grammatical description (e.g. Cognitive Grammar, Construction Grammar, or other schema-based theories of grammar) offers the prospects for a general theory of the nature and properties of causative constructions, one which can incorporate generalizations of all types and which would fit with the emerging view of grammar as serving the purpose of encoding the conceptualizations of its users.

Received 21 August 1991

Revision received 12 May 1993
University of California, San Diego

Utrecht University

\section{Notes}

* Portions of this paper were presented at the Department of Linguistics, University of California, Santa Barbara, and the Second International Conference on Cognitive Linguistics held at Santa Cruz, 1991. We are grateful to the linguists at Santa Barbara and the ICLA participants for useful discussions. For helpful comments on an earlier draft of this paper we would like to thank Richard Epstein, Dirk Geeraerts, S.-Y. Kuroda, Ronald Langacker, Lachlan Mackenzie, John Moore, and Leonard 
Talmy Verhagen's work on this project was supported by the Netherlands Organization for Scientıfic Research (NWO), grant S 30-317, and conducted withın the framework of the Free University Research Program "Functional Language Research Grammai and Pragmatics" (LETT/88-10) He wishes to thank the participants in this program for useful feedback Kemmer is grateful to UCSD students in the Cognitıve Linguistics Workıng Group and in her 1991 seminar on Event Structure for stimulating discussion

1 For a representative selection of literature of derivational accounts, see the references cited in Shibatanı (1976), Comrie (1981), Cole (1983), and Davies and Rosen (1988)

Rosen (1989) and Alsina and Josh (1991) are examples of lexical accounts unvolving predicate merger or fusion It should be noted that not all generative approaches involve reduction some accounts propose biclausal representations at all levels, and still others, monoclausal 1epresentations at all levels, some accounts also treat morphological and analytic causatives with different mechanisms See Davies and Rosen (1988), Rosen (1989), and Moore (1991) for discussion of the issues involved

2 In many languages, the expression for the causal predicate is termed by the grammar writer a "particle" or "auxiliary", indicating some lack of full verbal status Given that at least some verbal properties are almost always synchronically manifested by such elements, we extend the notion of "verb" to include them

3 What "causally dependent" means, we will not venture to say Shibatanı's (1976) characterization of $A$ causes $B$ in terms of the speaker's belief that the event B would not have happened without some prior action of A is a useful paraphrase, but seems also to be based on more fundamental notions comprising a mode of understanding the world that is very deeply rooted in human cognition For discussion, cf Turner (1987 ch 4) Fortunately, nothing in our analysts hinges on elucidating the notion of "causal dependence"

4 The syntactic mechanisms proposed in generative accounts such as these Relational Grammar clause union analyses are invoked to explain why the constructions display both monoclausal grammatical properties and properties associated with uncontroversially two-clause structures Causative constructions within and across languages differ in the degree to which they show such Janus-like behavior, but the association of such behavior with causative constructions in particular is extremely robust, and requires explanation We believe that the semantics of causative structures (mcluding the notion of partial conceptual fusion or "event conflation", cf Talmy 1992) must ultimately be part of that explanation

5 In some analyses of causatives, it is assumed or argued that events, rather than partıcipants, cause events (cf Wojcik 1976 170, Talmy 1976 53) While this may be reasonable phenomenologically, it is also clear that human languages tend, wherever possible, to impute causes to participants, especially when a human being is perceived as the direct initiator of the causing event

6 We use the term "affectee" because the participant in question is in the most prototyp1cal cases affected by the causal event In some case physical energy transfer is not at issue, but rather sumply a schematic path directed towards the entity In I made her read the letter, for example, the letter may not be physically affected, but nevertheless there is a conceived flow of (abstract) energy transmitted from causer through causee to the letter, which is where the causee's interest and attention end up being focussed See Givon (1984 ch 3, ch 4) and Langacker (1991 ch 7) for discussion of this general model of transitivity

7 The types mentioned are taken from the semantic causative typologies established by Shibatanı $(1973,1976)$ and Talmy $(1976,1988)$ See also Nedjalkov and Sil'nick1j 
(1973), Givon (1975), and the useful summary of the semantic parameters involved in causative constructions provided in Comrie (1981)

8 Shibatanı (1976) provides an excellent demonstration of how the set of available structural options in a language for particular effected predicates can interact with the possible meanings for the structure $\mathrm{He}$ also shows that causative structures can differ as to degree of specificity (e g the English analytic causative structure with the verb cause is less specific than those with the verbs make and have)

9 It is an accepted result in Cognitive Linguistics that transitivity is a matter of degree, and different languages respond in different ways to deviations from prototypical transitive and intransitive events (cf Hopper and Thompson 1980) But differences in degree of transitivity of the effected predicate are not relevant for our purposes in this paper

10 Other logical possibilities for structural differences include completely different constructions for ICs and TCs, different word order, and different agreement possibilities Examples of the first type are found in Guaran1, which has two different morphological causative markers, $-m y-/-m b o-$ and $-u k a m y$ - occurs with causatives of intransitives and $u k a$ with causatives of transitives (Maura Velazquez, personal communication), and in Mangarayı, in which a morphological causative marker is used to form causatives of one-participant events, while a sentence of the type 'I made her eat some cake' must apparently be rendered as 'I told her she should eat some cake' (cf Merlan 1982) Similarly, in Yidiny, although some transitive verbs occur with a morphological causative marker, the tendency is to use a verb like 'tell' instead (cf Dixon 1977) Word order differences have been explored to a certain extent, especially in connection with French, agreement marking differences between ICs and TCs have not to our knowledge been investigated (but see Mej1as-Bikand1 1989 for word order differences between specific causative constructions in Basque)

11 We are grateful to Aintzane Dorz-Bienzobas for providing us with these examples It should also be noted that there is another dialect of Basque in which all causees, whether in ICs or TCs, are marked with dative case (see Mejras-B1kandı 1989)

12 Alsina and Josh1 (1991) also acknowledge the importance of accounting for such semantic differences and attempt to link such differences with the thematic role structure of the predicate Their account differs from ours, among other things, in its ascription of all relevant information to lexical structures (which does not appear to leave room for constructional meanings) and in the fact that it does not allow an explanatory role for the semantics of the case markers

13 As far as we have determined, dative and instrumental are the most widespread cases found on causees of TC constructions There are a few other cases that occur on causees, such as comitative (e $\mathrm{g}$ in Hua) and certain locational cases such as ablative (e $g$ in Punjabi) We will not consider them here, but we believe that our account can easily be extended to incorporate them

14 The type of relation discussed here, it should be noted, is different from the type of extension, well-known by now in Cognitive Linguistics, involving a relation between a prototype and a (metaphorically or metonymically) related category (cf Lakoff 1987 and elsewhere) In the relation between the IC and the transitive clause prototype, the extended category is conceptually richer than its more basic counterpart with respect to both meaning and form, there is greater complexity Metaphorical extensions from a prototype, on the other hand, often preserve only schematic properties of their prototype (cf Lakoff 1990) and in that sense at least are less rich than the prototype

15 Shibatanı (to appear) argues that benefactive constructions cross-linguistically are based on a semantic schema involving a giving relation Similarly, Goldberg (1992) 
suggests that the ditransitive construction in English has a prototype associated with it that is based on the semantics of the predicate "give"

16 We are grateful to Ronald Langacker (personal communication) for reminding us of this fact

17 The analysis of causative structures provided by Langacker (1990 254-260) anticipates our own in that it motivates the case marking of causees in terms of the semantic properties shared by TC causees and dative-marked and instrumental-marked participants in simple clauses Our analysis in subsequent sections elaborates on these connections more fully

18 Our characterization has, as one might expect, antecedents in Linguistics For example, Jakobson (1966 68) states that the dative and the instrumental cases mark NP participants that occupy a "peripheral position" in the "entire conceptual content of the utterance'

19 Hyman and Zimmer (1976) contains many insightful observations on French causatives We regret that it came to our attention only as the final manuscript of this paper was being prepared

20 German does not allow dative markıng on causees, if the causee is not marked as agentive, it is marked as accusative

21 It would be interesting to ascertam whether contrasts of the Kannada type also show a topicality contrast e $g$ use of dative where the causee is more topical in the sense that what happens to the causee is at issue, and use of instrumental where what is important is bringing about a certain effect on the affectee, in the above case, getting the biscuit eaten

22 Our account shares some similarities with those of Cole (1983) and Saksena (1980), both of which focus on the importance of semantics in the determination of case marking It is interesting to note that Cole and Saksena, in formulating their accounts, focused on different aspects of the role of the causee in ICs and TCs Cole established degree of agentivity, corresponding here to autonomy, of the causee as important for case markang, while Saksena determmed that degree of affectedness of the causee also plays a significant role An important difference between these accounts and ours, however, is that, as far as we can see, neither Cole nor Saksena attribute any semantic content whatever to the case markers themselves

23 As mentioned in section 4 1, instrumental-marked causees can be viewed as metaphor1cal instruments The same can be sald for mstrumental-marked passive agents As such, we might expect that instrumental marking would have a strong association with inanimate participants Some partial support comes from Dutch, for the causees a recently collected corpus of Dutch causative constructions shows that agentive/ instrumental-marked causees are far more likely to be manimate than are causees marked by other case-marking options $50 \%$ of agentıve/instrumental (door) causees are inanimate, vs $10 \%$ of zero-marked causees and $0 \%$ of dative-marked (aan) causees (We are grateful to Nienke Landre and Nathalıe Lans for providing us with these data )

24 We discuss these differences in more detail in Verhagen and Kemmer (1992) Such differences constitute part of the reason why the examples in (9) are presented with different types of NPs it would be somewhat odd to use the personal pronoun haar in the dative (aan) and agentive/instrumental (door) cases because participants marked by these cases are lower in topicality than the unmarked object It would be useful to undertake a more detalled examınation of languages such as Hindi, to see if there, too, differences in type of NP (e g pronominal vs lexical) show up in discourse

Many linguists assume that grammaticization is incompatible with synchronic semantic 
motivation We see no reason to accept this assumption See Kemmer and Bat-Zeev Shyldkrot (forthcoming) for arguments against it

26 In fairness to Comrie, it should be noted that our account and his are directed toward essentially different aims Comrie seeks to predict, given a particular causative structure (IC or TC) and a set of case markers in a language, what case markıng will be found on the causee (this is the aim of many of the generative accounts cited in section 1) Predictability in this sense is not our aim, since what patterns of extension become conventionalized is not strictly predictable but only constrained Instead, our aim is to show how recurrent case-marking patterns found in association with causative structures are motivated by semantic facets of particular cognitive models of causative events We believe that a complete analysis of the semantics of the case markers used in causative constructions will make the case hierarchy essentially redundant

27 The examples in this section are taken from the Endhoven Corpus, an electronic database of Dutch described in uit den Boogaart (1975), including the subcorpus of government language described in Renkema (1981)

28 It is interesting to note that the subcorpus of government language is the only part of the corpus in which causative doen is more frequent than causative laten

29 This example was first suggested to us by Bob Kirsner

30 In the same questionnaire, we asked informants to judge doen-causatives with dative causees The results were remarkably similar to the situation with the instrumental most examples were rejected with $100 \%$ consensus In a few cases we had artificially maximized the possibility of an Experiencer reading for the causee (specifically by inserting see as effected predicate), in these cases, five out of eight informants rejected the sentences, and three accepted them, with different degrees of hesitation apparently these cases looked sufficiently like the standard phrase laten zlen, meaning 'show', that some informants did not wish to exclude the dative completely There is a general methodological point here, concerning the relation between the cognitive task of making acceptability judgments and the resulting judgments themselves, but we will not elaborate on it here

31 Bowerman (1979 286-287) points out that English make and let are among the first complement-taking verbs acquired by the child For more detalls, see Baron (1977 ch 5)

32 Langacker (1987) and Fillmore, Kay and O'Connor (1988 and elsewhere) have argued cogently against positing distınct grammatical components for handling idiomatic expressions and productive constructions

33 Comrie (1976) observes that Gilyak has a marker -ax which apparently occurs exclusively on causees, whether in ICs or TCs It is unclear whether this marker can be considered a "causee case marker", however, since the language does not have a case-marking system in the usual sense

\section{References}

A1ssen, Judith and David Perlmutter

1983 Clause reduction in Spanısh In Perlmutter, David M (ed), Studies in Relattonal Grammar 1, Chicago University of Chicago Press, 360-403

Alsina, Alex and Smita Joshi

1991 Parameters in causative constructions Papers from the 27th Regional Meeting of the Chicago Linguistic Soctety Chrcago Chicago Linguistic Society 
Anderson, Stephen R

1970 A little light on the role of deep structure in semantic interpretation NSF

Baron, Naomı S

Report No 26, II 1-II 13 Cambridge, MA Harvard University Press

1977 Language Acquisttion and Historical Change Amsterdam North-Holland

Boogaart, P C uit den

1975 Woordfrequenttes in geschreven en gesproken Nederlands [Word frequencies in written and spoken Dutch] Utrecht Oosthoek, Scheltema \& Holkema

Bowerman, Melıssa

1979 The acquisition of complex sentences In Fletcher, Paul and Garman, Michael (eds), Language Acquisition Cambridge Cambridge University Press, 285-305

Bybee, Joan and Willam Paghuca

1987 The evolution of future meaning In Ramat, A G et al (eds ), Papers from the Seventh International Conference on Histortcal Lingutstics Amsterdam and Philadelphia Benjamins, 109-122

Cole, Peter

1983 The grammatical role of the causee in universal grammar International Journal of American Linguistics 49, 115-133

Comrie, Bernard

1976 The syntax of causative constructions Cross-language similarities and divergencies In Shibatanı, Masayoshı (ed ), 261-312

1981 Language Untversals and Linguistic Typology Chicago University of Chicago Press

Croft, William A

1991 Syntactic Categortes and Grammatical Relattons The Cognttve Organtzation

D'Andrade, Roy G

of Information Chicago and London University of Chicago Press

1987 A folk model of the mind In Holland, Dorothy and Quinn, Naomı (eds ), Cultural Models in Language and Thought Cambridge Cambridge University Press, 112-148

Davies, Wilham and Carol Rosen

1988 Union as mult1-predicate clauses Language 64, 52-88

Delancey, Scott

1984 Notes on agentivity and causation Studies in Language 8, 181-213

Dik, Simon C

1980 The Dutch causative construction In Studies in Functional Grammar London/New York Academic Press, 53-89

Dixon, $\mathrm{R} \mathrm{M}$ W

1977 A Grammar of Yidiny Cambridge Cambridge University Press

Fillmore, Charles

1977 The case for case reopened In Cole, $\mathbf{P}$ and Sadock, J M (eds), Syntax and Semanttcs 8 Grammatıcal Relatıons New York Academıc Press, 59-81

Fillmore, Charles, Paul Kay and Mary Catherine O'Connor 1988 Regularity and idiomaticity The case of let alone Language 64, 501-538

Gibson, Jeanne and Eduardo Raposo

1986 Clause union, the Stratal Uniqueness Law and the chomeur relation Natural

Givon, Talmy

Language and Linguistic Theory 4, 295-331

1975 Cause and control On the semantics of interpersonal manipulation Kumball, J (ed ), Syntax and Semantıcs 4 New York Academic Press 
1984

Syntax A Functional-Typological Introduction Vol 1 Amsterdam and

Goldberg, Adele Philadelphia Benjamins

1992 Argument Structure Constructtons Doctoral dissertation, University of Calıfornia at Berkeley

Haman, John

1983 Iconic and economic motivation Language 59, 781-819

Hetzron, Robert

1976 On the Hungarian causative verb and its syntax In Shıbatanı, Masayosh1 (ed ), 371-398

Hopper, Paul and Sandra A Thompson

1980 Transitivity in grammar and discourse Language 56, 251-299

Hyman, Larry and Karl M Zimmer

1976 Embedded topic in French In L1, Charles N (ed), Subject and Topic New

York Academic Press, 189-211

Jakobson, Roman

1966 Beitrag zur allgemeınen Kasuslehre Gesamtbedeutungen der russischen

Kasus In Hamp, E P et al (eds ), Readings in Lingulstics II Chicago and

London University of Chicago Press, 51-89

Kemmer, Suzanne and Hava Bat-Zeev Shyldkrot

forthcoming

The semantics of "empty prepositions" in French Paper presented at the Second International Cognitive Linguistics Association Conference, Santa Cruz, 1991 To appear in Casad, Eugene (ed ), Cognttive Linguistics in the Redwoods (Cognitive Linguistics Research series) Berlın/New York Mouton de Gruyter

Kursner, Robert S

1988 Prepositional versus "bare" indirect objects in the written Dutch of novels and newspapers In Broos, T (ed), Papers from the Third Interdisciplinary Conference on Netherlandic Studies Lanham, MD University Press of America, 279-296

Kirsner, Robert S, Arie Verhagen and Mariette Willemsen

1985 Over PP's, transitiviteit en het zgn indirekt objekt [On PPs, transitivity, and the so-called indirect object] Spektator 14, 341-347

Kuroda, S - Y

1992 The lexical and the productive causatives in Japanese An examination of the theory of the paradigmatic structure Ms, Unversity of Calıfornia, San Diego

Lakoff, George

1987 Women Fire, and Dangerous Things What Categortes Reveal about the Mind Chicago University of Chicago Press

1990 The invariance hypothesis Is abstract reason based on mage-schemas? Cognttve Linguistics 1, 39-74

Langacker, Ronald W

1987 Foundations of Cognitive Grammar Vol I Theoretical Prerequisites Stanford Stanford University Press

1990 Transitivity, case, and grammatical relations In Concept, Image, and Symbol The Cognttve Basts of Grammar Berlin/New York Mouton de Gruyter, 209-260

1991 Foundations of Cognitive Grammar Vol II Descriptive Application Stanford Stanford University Press 
L1, Charles (ed)

1977

Mechanisms of Syntactic Change Austin and London University of Texas Press

Matisoff, James A

1976 Lahu causative constructions Case hieiarchies and the morphology/syntax cycle in a Tibeto-Burman perspective In Shibatanı, Masayoshi (ed), 413-442

Mejlas-Bıkand, Errapel

1989 Causative constructions in Basque Ms, University of Calıfornia, San Diego

Merlan, Francesca

1982 Mangarayı (Lingua Descriptive Series 4 ) Amsterdam North-Holland

Moore, John

1991 Reduced Constructions in Spantsh Doctoral dissertation, Unversity of California, Santa Cruz

Nedjalkov, V P and G G Sil'nıckı

1973 The typology of morphological and lexical causatives In Kiefer, Ferenc (ed ), Trends in Soviet Theoretical Lingustics Foundations of Language,

Renkema, Jan Supplementary Series 18 Dordrecht Reidel, 1-32

1981 De taal van 'Den Haag" een kwantitatief-sttlistisch onderzoek naar aanleuding van oordelen over taalgebrutk [The language of "The Hague" a quantitative stylistic anvestigation motivated by judgments on usage] 's-Gravenhage

Rice, Sally Staatsuitgeveri]

1987 Towards a Cognittve Model of Transittvity Doctoral dissertation, University of California, San Diego

Rosen, Sarah

1989 Argument Structure and Complex Predicates Ph D dissertation, Brandeis University

Saksena, Anhuradra

1980 The affected agent Language 56, 812-825

Shrbatanı, Masayoshı

1973 A Lingutstic Study of Causative Constructions Ph D dissertation, University of Calıfornia at Berkeley

1976 The grammar of causative constructions A conspectus In Shibatanl, Masayoshı (ed ), 1-40

to appear Applicatives and benefactives A cognitive account

Shibatanı, Masayoshı (ed)

Talmy, Leonard

1976 Syntax and Semantics 6 The Grammar of Causative Constructions New York Academic Press

1976 Semantic causative types In Shibatanı, Masayosh1 (ed ), 43-116

1988 Force dynamics in language and cognition Cognttve Sctence 12, 49-100

1992 A typology of event conflation Ms, State Unıversity of New York, Buffalo

Tuggy, David

1988 Nahuatl causative/applicatives in Universal Grammar In Rudzka-Ostyn, Brygida (ed), Toptcs in Cognttve Lingutstics Ansterdam Benjamun, 587-618 
Turner, Mark

1987 Death is the Mother of Beauty. Chicago and London: University of Chicago Press.

Verhagen, Arie and Suzanne Kemmer

1992 Interactie en oorzakelijkheid: Een cognitieve benadering van causatiefconstructies in het Nederlands [Interaction and causation: A cognitive approach to causative constructions in Dutch]. Gramma/TTT, Tijdschrift voor taalkunde 1, 1-20.

Wojcik, Richard H.

1976 Where do instrumental NPs come from? In: Shibatani, Masayoshi (ed.), 165-180. 